\title{
La ciudad invisibilizada: una aproximación a los falsos vacantes \\ en el Partido de La Plata
}

\section{The invisible city: an approach to false vacancie lands \\ in La Plata District}

\begin{abstract}
Julieta Frediani*
Instituto de Investigación y Políticas del Ambiente Construido, Facultad de Arquitectura y Urbanismo, Universidad Nacional de La Plata. jfrediani@yahoo.com

Daniela Cortizo** Instituto de Investigación y Políticas del Ambiente Construido, Facultad de Arquitectura y Urbanismo, Universidad Nacional de La Plata. cortizodaniela@gmail.com
\end{abstract}

Rocío Rodriguez Tarducci*** Instituto de Investigación y Políticas del Ambiente Construido, Facultad de Arquitectura y Urbanismo, Universidad Nacional de La Plata. rociotarducci@gmail.com

\section{Ma Luciana Giglio****} Instituto de Investigación y Políticas del Ambiente Construido, Facultad de Arquitectura y Urbanismo, Universidad Nacional de La Plata. giglio.luciana@hotmail.com

Fecha de envío: 31/10/2018| Fecha de aceptación: 03/06/2019 | Fecha de publicación: JUNIO 2019

* Doctora en Geografía, Facultad de Humanidades y Cs. de la Educación. UNLP. Licenciada y Profesora en Geografía egresada de Ia UNLP. Investigadora Adjunta CONICET. Docente-Investigador del Instituto de Investigación y Políticas del Ambiente Construido (FAU- UNLP). Profesor de la Cátedra de Metodología y Técnicas de la Investigación en Geografía (Depto. de Geografía-FaHCE-UNLP) y de la Cátedra de Planificación Territorial I (FAU-UNLP). Docente en la Maestría de Cs de Territorio y en la Maestría de Paisaje, Medioambiente y Ciudad (FAU-UNLP). Ha trabajado en Planificación Estratégica Urbana y Municipal (UNLP).

**Arquitecta egresada de la Facultad de Arquitectura de la UNLP. Becaria Doctoral CONICET en el Instituto de Investigaciones y Políticas del Ambiente Construido (FAU-UNLP), maestranda en Maestría en Cs del Territorio (FAU-UNLP), y doctoranda en Geografía en la Facultad de Humanidades y Cs de la Educación (FaHCE-UNLP). cuyo tema es "Las tierras vacantes en el Partido de La Plata: Gestión del suelo y lógicas del mercado". Participo del proyecto PPID/U007 denominado "Problemáticas territoriales y ambientales de las periferias urbanas del Gran La Plata. Aproximaciones teórico metodológicas a n crecimiento urbano con grandes espacios vacantes".

*** Arquitecta egresada de la Facultad de Arquitectura de la UNLP. Becaria Doctoral CONICET en el Instituto de Investigaciones y Políticas del Ambiente Construido (FAU-UNLP), Doctoranda en Geografía en la Facultad de Humanidades y Cs de la Educación (FaHCE-UNLP) cuyo tema de investigación es "Procesos de ocupación y apropiación territorial en el partido de La Plata. El caso de los asentamientos de origen informal surgidos durante el periodo 1989-2015". Participa del proyecto PPID/U007 denominado "Problemáticas territoriales y ambientales de las periferias urbanas del Gran La Plata. Aproximaciones teórico metodológicas al crecimiento urbano con grandes espacios vacantes".

**** Arquitecta (Universidad Nacional de La Plata) y Becaria de Investigación Doctoral CONICET en la Línea 2 del Instituto de Investigaciones y Políticas del Ambiente Construido (CONICET -UNLP). Miembro del Observatorio de Movilidad Urbana de Gran La Plata (OMUGLP). Estudiante de Doctorado en Estudios Urbanos (ICO-UNGS). Ha participado como ponente en eventos académicos, talleres y congresos nacionales e internacionales sobre urbanismo, territorio y transporte. 


\section{Resumen}

El objetivo del presente trabajo consiste en el análisis de la problemática de los falsos vacantes en las periferias del Partido de La Plata, es decir, de aquellas áreas ilegalmente ocupadas pero consideradas oficialmente como vacantes u ocupaciones transitorias.

Por su condición de informalidad, estos espacios terminan convirtiéndose en "invisibles" para las administraciones públicas. Este trabajo pretende contribuir, a partir de la construcción de la categoría "falso vacante", a la visibilización de los asentamientos informales en el Partido de La Plata y al reconocimiento de posibles estrategias de intervención estatal que permitan dar respuesta a esta temática. Así, los "falsos vacantes" sintetizan dos complejas problemáticas que caracterizan a estos territorios de borde: la vacancia del suelo y la informalidad urbana. Es precisamente en estas periferias donde se desarrolla la no-ciudad, es decir, se produce un proceso de urbanización sin ciudad. La presión por el acceso al suelo da lugar a desarrollos por vía de la informalidad, en donde el Estado se encuentra, ya sea por acción o por omisión, prácticamente ausente.

Palabras claves: Falsos vacantes; Asentamientos informales; Periferias urbanas.

\section{Abstract}

The objective of this paper is to analyze the problem of false vacancie lands in the peripheries of the La Plata, Buenos Aires Argentina. That is, those „illegally occupied areas but officially considered as vacancie lands or transitory occupations. This paper aims to contribute to the discussion around the importance and meanings of the visibility and representation of informal settlements on city maps. In this way, the "false vacancie lands" summarize two complex problems that characterize these border territories: the vacancy of the land and urban informality. It is precisely in these peripheries where the non-city develops, that is, a process of urbanization without a city takes place. The pressure of people for achive the access to land gives rise to developments through informality, where the State is absent.

Keywords: False vacant land; Informal settlements; Urban peripheries. 


\section{Introducción}

En las últimas décadas, la expansión urbana en el contexto latinoamericano ha sido acompañada por la ocupación de nuevas superficies en áreas periféricas de las ciudades. En estas áreas caracterizadas por su dinamismo, por su heterogeneidad, como así también por sus condiciones de degradación y fragilidad ambiental, los espacios vacantes se constituyen en áreas de atracción para los diferentes actores sociales que intervienen en el proceso expansivo, tanto a través de la modalidad de urbanización formal como de la informal, contribuyendo al logro de periferias socio-territorialmente fragmentadas. Es precisamente en estas periferias donde se desarrolla la no-ciudad ${ }^{1}$, es decir, se produce un proceso de urbanización sin ciudad, y en donde la toma de tierra se constituye en la modalidad predominante de acceso al suelo por parte de los sectores de menores ingresos.

Sin embargo, cabe destacar que esta modalidad informal de urbanización del suelo representa, en palabras de Tardin (2006), una "geografía a menudo invisible a los ojos de muchos ciudadanos". Estas periferias, destinadas a la población de más bajos ingresos y a los excluidos del mercado de trabajo, son denominadas por Hidalgo et al. (2008) como "precariópolis". En ellas se pone de manifiesto una lógica del Estado incapaz de dar respuesta a la problemática de la informalidad urbana, que se manifiesta en una dispersión azarosa de estos asentamientos y una ubicación de los mismos en proximidades de canteras y basurales, como así también en las planicies de inundación de los arroyos. Cabe preguntarse en este punto: ¿es la invisibilidad de los barrios informales lo que determina la ausencia o escasez de políticas destinadas a atender a las necesidades de sus habitantes? o ¿es la

1. El concepto de "no ciudad" hace referencia a "una especie de caos urbano que había proliferado preferiblemente en la zonas periurbanas y que se percibía como un desmoronamiento de lo urbano como forma de vida en favor de una ciudad difusa, fundamentada es asentamientos expandidos que se antojaban a espaldas a cualquier cosa que se pareciese a un espacio realmente socializado y socializador" (Delgado, M., 2003: 123).

Este concepto se vincula fuertemente al concepto de "no lugar" de Marc Augé (2000). Al respecto, "si un lugar puede definirse como lugar de identidad, relacional e histórico, un espacio que no puede definirse ni como espacio de identidad ni como relacional ni como histórico, definirá un no lugar" (Marc Augé, 2000: 83). falta de respuesta a esta problemática desde el Estado lo que les proporciona invisibilidad a estos asentamientos?².

Las periferias urbanas del Partido de La Plata son escenario de dos problemáticas estrechamente vinculadas: por un lado, la vacancia del suelo, es decir, la existencia de tierra ociosa o abandonada carente de uso, y por otro, la urbanización informal, resultante de las dificultades de acceso al suelo por parte de la población de bajos recursos, y que encuentra en las tierras vacantes -fiscales o privadas- su lugar de residencia. La falta de acceso legal a la tierra, al suelo y a la vivienda convierte a estos asentamientos en áreas frecuentemente no reconocidas por parte del Estado, dando lugar a los denominados "falsos vacantes"3. En el Partido La Plata, según el informe del Registro Público de Villas y Asentamientos de la Provincia de Buenos Aires (2015), existe un total de 128 urbanizaciones informales (entre villas, asentamientos precarios y otros tipos de urbanizaciones informales) lo que repre-

2. En relación al concepto de "invisibilidad" cabe destacar que el mismo da cuenta tanto de la falta de reconocimiento de los ciudadanos -que no conocen la periferia- como de la falta de reconocimiento en los registros públicos por parte del Estado. Al respecto cabe citar los trabajos de Cáceres, R.; Cáceres, E. (2016); Baeza, M. A. (2000) y Calvino, I. (1999) que abordan el tema de la invisibilidad asociada a las identidades en las periferias urbanas, a la realidad social y a la ciudad, respectivamente. A los fines del presente trabajo se focalizará en la invisibilización de los asentamientos informales por parte del Estado, tomando como ejemplo de esta última a los registros del Ente Provincial ARBA (Agencia de Recaudación de la Provincia de Buenos Aires). Si bien, no se desconoce la imposibilidad de realizar generalizaciones respecto de la invisibilidad en que sostiene el Estado a estos barrios informales a partir del estudio de caso propuesto, se considera un ejemplo sumamente valioso e importante dado que es el ente autárquico responsable de administrar la política tributaria de la provincia de Buenos Aires (con aproximadamente 16 millones de habitantes al año 2010 según datos del INDEC). Creado en 2007 -por medio de la ley 13.766- como instancia superadora de sus antecesoras: la Subsecretaría de Ingresos Públicos, la Dirección Provincial de Rentas y la Dirección Provincial de Catastro, mantiene fuertes vínculos con los todos municipios de la Provincia de Buenos Aires, a través de relaciones de cooperación, asistencia técnica e intercambio de información. Este organismo provincial es el encargado del cobro de los impuestos inmobiliario y catastro, entre otros, siendo sus registros cartográficos utilizados en la mayoría de los municipios de la provincia.

3. Al respecto, y como se señala desde la página oficial de ONU-Hábitat en "Poner los asentamientos informales en el mapa": "A menudo, los asentamientos informales no aparecen en los mapas oficiales de una ciudad. Sin embargo, el mapeo es esencial para la mejora de estas áreas". Recuperado el 23 de Mayo de 2019 en: https://onuhabitat.org.mx/index.php/hacer-de-los-asentamientos-informales-parte-de-la-ciudad 
senta alrededor de 20.800 familias. Estas cifras permiten cuantificar la informalidad urbana y dimensionar la importancia del tema.

En este marco, el abordaje metodológico implementado en el presente trabajo ha sido de tipo cuali-cuantitativo, de modo de poder abordar en su totalidad la complejidad de la realidad estudiada. Para llevar a cabo dicho abordaje metodológico, en principio se accedió a la información del ente autárquico provincial encargado de administrar la política tributaria: ARBA (Agencia de Recaudación de la Provincia de Buenos Aires). Esta información, junto con la obtenida a partir del Registro Público Provincial de Villas y Asentamientos Precarios de la Provincia de Buenos Aires ${ }^{4}$, permitió contrastar con las tierras que actualmente presentan una ocupación informal, pero que al mismo tiempo figuran oficialmente para esta institución como vacantes.

Asimismo, para el análisis de la información obtenida, se utilizaron herramientas como la fotolectura de imágenes satelitales, el entrecruzamiento de información primaria y secundaria en un Sistema de Información Geográfica (SIG) y la posterior construcción de cartografía temática. A partir de los resultados del análisis se llevó a cabo una clasificación de la totalidad de urbanizaciones informales, lo que permitió identificar la existencia de falsos vacantes -para el mencionado Ente Autárquico Provincial (ARBA)-, como así también de otras modalidades de ocupación informal.

Finalmente, cabe señalar que el objetivo principal que guía la realización del presente trabajo consiste en el análisis de la problemática de los falsos vacantes en las periferias del Partido de La Plata, es decir, de aquellas "áreas informalmente ocupadas" (invasiones, tomas de tierra, etc.) pero consideradas desde algunas dependencias del Estado como vacantes o con ocupaciones transitorias. En este marco, resulta importante destacar que en la indagación bibliográfica a nivel nacional no se han encontrado trabajos académicos referentes al concepto de los "falsos vacantes"; por lo que este artículo

4. Subsecretaría Social de Tierras, Urbanismo y Vivienda (2015) "Registro Público Provincial de Villas y Asentamientos Precarios". Ministerio de Infraestructura y Servicios Públicos. Provincia de Buenos Aires. Disponible en: http://190.188.234.6/mapa/ representa un puntapié inicial para el estudio de esta problemática ${ }^{5}$.

\section{Periferias invisibilizadas: los falsos vacantes}

Abordar la problemática de la ciudad invisibilizada apunta a la necesidad de visualizar la "ciudad oculta, que no vemos, no queremos ver o pretendemos que no se vea" (Biedermann et al., 2018). El tema de la visibilidad va más allá de las características físicas del territorio e involucra la vida social que tiene lugar en estos sectores urbanos vulnerados -generalmente áreas periféricas de las ciudades-, las necesidades de su población y los conflictos existentes en los mismos. En este sentido, en la ciudad contemporánea, y particularmente en sus periferias urbanas, se torna de fundamental importancia visibilizar tanto la compleja trama de relaciones sociales y de poder, como la materialización físico-espacial de las mismas.

En las periferias pueden reconocerse diferentes formas de urbanización informal que constituyen paisajes invisibles, es decir, paisajes que no se ven, y que, por lo tanto, no se conocen. Estos paisajes incógnitos requieren ser descifrados a partir de claves acerca de quiénes los ven y cómo los viven (Lindón, 2007 en: Cáceres et al., 2016).

Como señalan Cáceres et al. (2016), la cuestión de la invisibilidad es una manera de ocultar a la ciudad que no responde a los "cánones establecidos", aquella que conforma la ciudad informal, ilegal o irregular, la que asienta a sectores pobres de la sociedad. El paisaje urbano "invisibilizado" es el que se encuentra alejado, aquel que no responde a normativas urbanísticas, ese que está en constante autoconstrucción.

En este marco, los actuales procesos de urbanización que se dan en las ciudades latinoamericanas se encuentran caracterizados por la dispersión y la ruptura de los vínculos de continuidad como fundamento de una nueva forma de ser

5. El presente trabajo está enmarcado en el proyecto PPID denominado "Problemáticas Territoriales y Ambientales de las Periferias Urbanas del Gran La Plata. Aproximaciones teórico-metodológicas a un Crecimiento Urbano con Grandes Espacios Vacantes". A su vez, la temática estudiada tiene su origen en la unión de dos tesis de doctorado, sobre las tierras vacantes y los asentamientos informales. 
de lo urbano. El avance de la ciudad hacia áreas rurales, con las consecuentes variaciones en los usos del suelo, da origen a un nuevo tejido urbano, flexible y disperso, donde los límites se tornan cada vez más imprecisos.

Las nuevas formas urbanas poseen un carácter marcadamente insular, con características que subrayan la "tendencia hacia una ciudad extremadamente segregada y dividida" (Max Welch Guerra, 2005). Las estructuras insulares de la ciudad latinoamericana, se han convertido en elemento determinante de la transformación y el desarrollo del espacio urbano.

En las últimas décadas, la ciudad se ha ido expandiendo con bajas densidades, dejando espacios intersticiales sin ocupar, configurando así un modelo de ciudad dispersa. Estos espacios vacantes o intersticios urbanos se constituyen en rasgos característicos de la ciudad en general, y de las periferias urbanas, en particular. Cabe destacar que se entiende por tierra vacante urbana a una porción delimitada de suelo, establecida como urbana por el código vigente, que no se encuentra utilizada ( $\sin$ uso), siendo espacios remanentes a la dinámica urbana, que no se desarrollan en la plenitud de su potencial, contrariando el principio de función social de la propiedad (Clichevsky, 2007; Fausto Brito y Rábago, 2001).

El corrimiento del "límite" urbano ha sido acompañado por la proliferación de espacios intersticiales, muchos de los cuales se encuentran localizados en áreas con déficit de infraestructura de servicios básicos como así también en áreas inundables, lo cual demanda grandes inversiones por parte del Estado para urbanizarlos. Pero a su vez, existen predios vacantes con infraestructura de servicios subutilizada al interior del área urbana, con buena accesibilidad, muchos de ellos retenidos por una especulación inmobiliaria, entre otras causas.

Las periferias urbanas constituyen así un territorio desordenado, cargado de conflictos y contradicciones, un lugar en el cual las influencias del centro se entremezclan de manera imprevista con las condiciones impuestas por el medio, dando lugar a configuraciones inéditas y a veces equívocas. La condición periférica puede caracterizarse como una condición de estado incompleto.
Las periferias urbanas son escenario de distintas lógicas que permitirían diferenciar una periferia destinada a la población de ingresos altos y medio-altos, territorio distintivo y característico de la denominada "privatópolis inmobiliaria", de una periferia destinada a la población de más bajos ingresos y a los excluidos del mercado de trabajo o "precariópolis" (Frediani, 2010). Es en este último tipo de periferia, caracterizada por procesos de degradación física y social, en donde se localizan los asentamientos informales, generalmente en entornos desfavorables, áreas de borde y de fragilidad ambiental.

La periferia resulta así un espacio socioeconómicamente muy complejo, en donde los procesos de segregación socio espacial adquieren una particular intensidad ${ }^{6}$.

Frente a la necesidad actual de tierras para la construcción de viviendas, los espacios vacantes se constituyen en una atracción para los diferentes grupos sociales, que "compiten" por estos espacios intersticiales: sectores de menores recursos a través de las tomas de tierras, sectores sociales de clase media en busca de terrenos para la casa propia y sectores de mayores recursos para la construcción de viviendas en urbanizaciones cerradas. En este sentido, es posible reconocer, periferias ricas en oportunidades, producto de desarrollos inmobiliarios (urbanizaciones cerradas), y periferias pobres en oportunidades, producto de la expulsión de la ciudad (urbanizaciones informales) (Frediani, 2010).

La problemática de la tierra vacante se relaciona estrechamente con la toma de tierras y los proce-

\footnotetext{
6. En relación al concepto de segregación, desde el enfoque clásico del concepto, Rodríguez Merkel (2014) señala que el término "segregación residencial ha sido -y sigue siendo- mayormente utilizado para designar la simple constatación empírica de que familias o individuos de similares características tienden agruparse en el espacio, es decir, a localizar sus residencias más próximos entre si que respecto a otros grupos. Este enfoque clásico se caracteriza por conceptualizar la segregación residencial como una simple relación espacial, donde cualquier grupo desigualmente distribuido en el espacio es un grupo segregado, y que se da entre grupos, sin discriminar entre los grupos segregados propiamente dichos y aquellos grupos que los segregan. Dentro de este enfoque se reconocen generalmente dos grandes tipos o clases de segregación: la étnica o racial por un lado (grupos definidos por su nacionalidad, religión, raza, etnia, idioma, etc.) y la socioeconómica por el otro (nivel de ingresos, educación, categoría ocupacional, etc.)".
} 
sos de autoproducción del hábitat, ya que son muchas de las tierras vacantes de las ciudades las receptoras de las ocupaciones irregulares de suelo.

En las ciudades latinoamericanas, la ciudad informal conforma una parte considerable del suelo urbano, habiéndose incrementando de manera significativa en las últimas décadas y convertido así en la forma principal de desarrollo del suelo urbano (Viana, 2007). Se estima que aproximadamente un 44\% de la población urbana de la región vive en áreas informales debido a que no pueden pagar ni obtener el acceso legal al suelo urbano; cifra que podría crecer rápidamente si no se toman medidas efectivas para revertir este proceso.

Entre los principales factores que permitirían explicar el proceso de urbanización informal puede reconocerse: por un lado, el elevado precio del suelo urbano residencial en el mercado formal; el cual deja excluidos a los sectores de menores ingresos, quienes sólo pueden acceder a la tierra en condiciones informales. Por otro lado, la ausencia de obras de urbanización formalmente requeridas, la baja calidad y dificultad en el acceso a la tierra y fundamentalmente la falta de seguridad jurídica que hacen que los precios en el mercado informal de suelos sean relativamente menores que en el mercado formal. Por estos motivos es que las urbanizaciones espontáneas y la informalidad urbana suelen ser dos características de las áreas de residencia de los sectores sociales más excluidos.

La urbanización informal es llevada a cabo en parte por aquellos que no tienen la posibilidad de comprar una vivienda o adquirir una renta en el mercado formal, ni son beneficiarios de políticas habitacionales públicas, es decir, son personas que se encuentran impedidas de habitar la ciudad por la vía formal.

Según Clichevsky (2000) la informalidad urbana puede ser vista en base a dos puntos de vista: por un lado, la informalidad desde el punto de vista dominial al referirse a la ocupación de tierra privada o fiscal en villas, asentamientos informales, loteos clandestinos, etc. Por otro lado, se refiere a la informalidad desde el punto de vista de la urbanización, es decir a la ocupación de tierras sin condiciones urbano-ambientales para ser usadas como residenciales.

En Argentina, las formas de urbanización informal más extendidas son las villas, los asentamientos informales, los loteos irregulares y los loteos clandestinos. Al respecto Cravino (2008), identifica, por un lado, a las villas como "urbanizaciones (o auto urbanizaciones) informales producto de ocupaciones de tierra urbana vacantes o de la afectación de tierras fiscales por el Estado para asentar familias provisoriamente". Por otro lado, la autora identifica como tipología a los asentamientos informales o tomas de tierra diferenciándolos de las villas desde el proceso mismo de la toma de tierra, que en el caso de los asentamientos informales se da de manera organizada, mientras que en el caso de las villas este proceso es espontaneo y de manera gradual. Otra diferencia tiene que ver con la regularidad de la trama, siendo que en el caso de los asentamientos informales la misma pretende continuar con la trama urbana "formal" para, en el futuro, lograr la regularización de manera más rápida, mientras que en las villas la trama es muy irregular debido a la espontaneidad en la ocupación.

En la Provincia de Buenos Aires, el Registro Público de Villas y Asentamientos informales define a la villas como urbanizaciones o auto urbanizaciones informales producto de ocupaciones de tierra urbana vacante o de la afectación de tierras fiscales por el Estado para asentar a las familias provisoriamente, cuyas características son tramas irregulares, viviendas construidas con materiales precarios, alta densidad poblacional, escaso o nulo espacio verde e infraestructura auto provista. A su vez, define a los asentamientos precarios como los barrios informales (en términos dominiales) con trazados urbanos que tienden a ser regulares y planificados, y que generalmente (aunque no de modo excluyente) cumplen algunas de las siguientes características: son decididos y organizados colectivamente, los ocupantes buscan legitimarse como propietarios, las viviendas tienen algún grado de firmeza y su ubicación puede encontrarse en tierras degradadas. La complejidad de la realidad urbana-habitacional, exigió abrir una tercera categoría que se denominó "Otro" con el objetivo de incluir una serie de barrios con situaciones 
Figura 1: Crecimiento del área urbana 1990-2001-2010

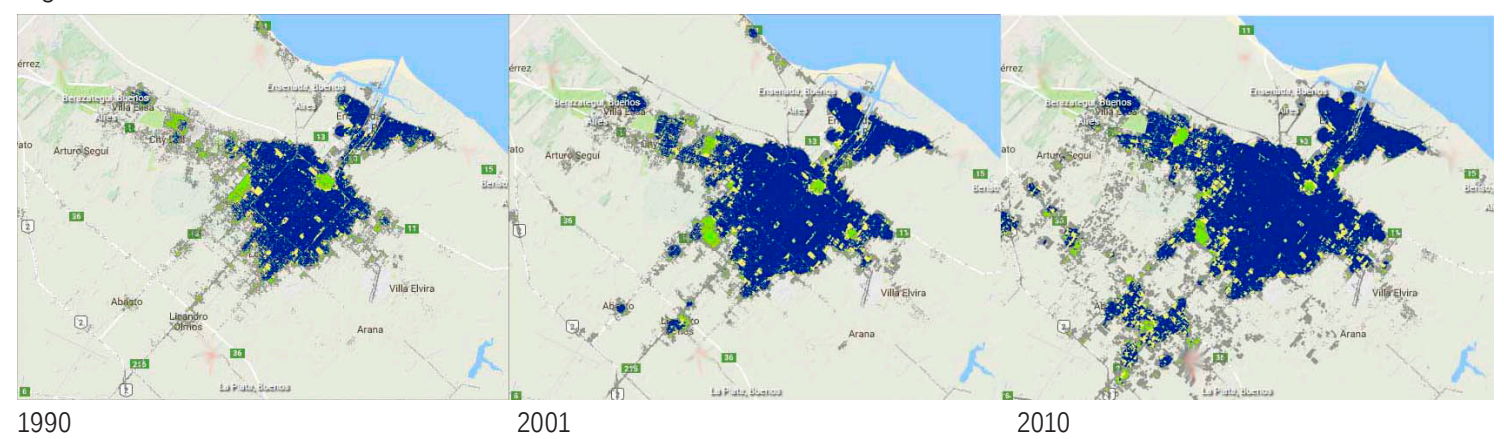

Fuente: Atlas de Crecimiento Urbano. Centro de Investigación de política urbana y vivienda. Universidad Torcuato di Tella. Disponible en: http://atlasurbano.herokuapp.com/\#/

particulares (edificios o casas tomados, fábricas abandonadas, loteos piratas, inquilinatos, etc.) que conforman parte de la misma problemática.

Es importante destacar que en las últimas décadas, se ha intensificado fuertemente la aparición de asentamientos informales en las distintas periferias de las ciudades cabecera del país ${ }^{7}$, caracterizados por invasiones masivas de predios vacantes (fiscales y/o particulares desocupados) ${ }^{8}$.

La presión por el acceso a la tierra da lugar a desarrollos por vía de la irregularidad, con la construcción de viviendas donde la infraestructura y los servicios urbanos no están disponibles, definiendo una categoría que se podría considerar como "falsos vacantes". Es frecuente que estas áreas ilegalmente ocupadas se consideren oficialmente como vacantes o con ocupaciones transitorias. Por su doble condición de irregulares (desde el punto de vista urbanístico) e ilegales (desde el punto de vista de la tenencia de la tierra) se convierten en espacios "invisibles" para las administraciones públicas. Visibles o no, sus impactos sobre la calidad de vida de la población y

7. Fuente: TECHO, Relevamiento de Asentamientos Informales - 2016, y Relevamiento Nacional de Barrios Populares (RENABAP) a Mayo del 2017. De acuerdo con el relevamiento de Techo, al 2016 existía un total de 2.432 asentamientos en ciudades y áreas metropolitanas de 11 provincias, en las que se estimó que habitan aproximadamente 650.700 familias (2.993.151 personas).http://relevamiento.techo.org.ar/downloads/informe relevamiento_TECHO_2016.pdf

8. En la provincia de Buenos Aires existen 1.585 barrios caracterizados como informales, donde viven 419.000 familias, de los cuales más de un cuarto están ubicados en localidades del interior bonaerense, según datos difundidos por el gobierno de la provincia de Buenos Aires (Fuente: Registro Público de Villas y Asentamientos informales, 2015) el conjunto de la ciudad no dejan, en ningún momento, de ser palpables (Larangeira, 2004).

En este contexto, frente al aumento de la población que vive en la informalidad, y la dificultad de brindar un hábitat adecuado a través de las políticas de viviendas públicas que se implementaban tradicionalmente, los gobiernos han encarado, especialmente desde la década del noventa del siglo pasado, múltiples programas y proyectos de legalización del dominio del suelo y regularización urbana y, en menor medida, políticas preventivas, tendientes a mejorar la situación urbana de dichos hábitat informales y/o solucionar la situación de tenencia (Clichevsky, 2006). Sin embargo, salvo excepciones, la mayoría de los programas de regularización aún se hallan desvinculados de la política urbana en su conjunto. Incluso entre los programas que se implementan en los últimos años, sólo unos pocos poseen relación con el área urbana en el cual se localizan. Esta situación no tiene relación exclusiva con quien formula e implementa los programas, sino más bien con la forma de llevar a cabo la política urbana, de manera sectorizada y desarticulada, en cada realidad.

\section{Urbanizaciones informales y tierras vacantes en el Partido de La Plata}

El Partido de La Plata ${ }^{9}$ registró al año 2010 una población de 654.324 habitantes, y una superficie de 88.887 ha (Censo 2010, INDEC). Del total

9. Se ubica a $56 \mathrm{~km}$ al sudeste de la Ciudad de Buenos Aires, y contiene a la Ciudad de La Plata, capital de la Provincia de Buenos Aires. 
Figura 2: Urbanizaciones informales en el Partido de La Plata

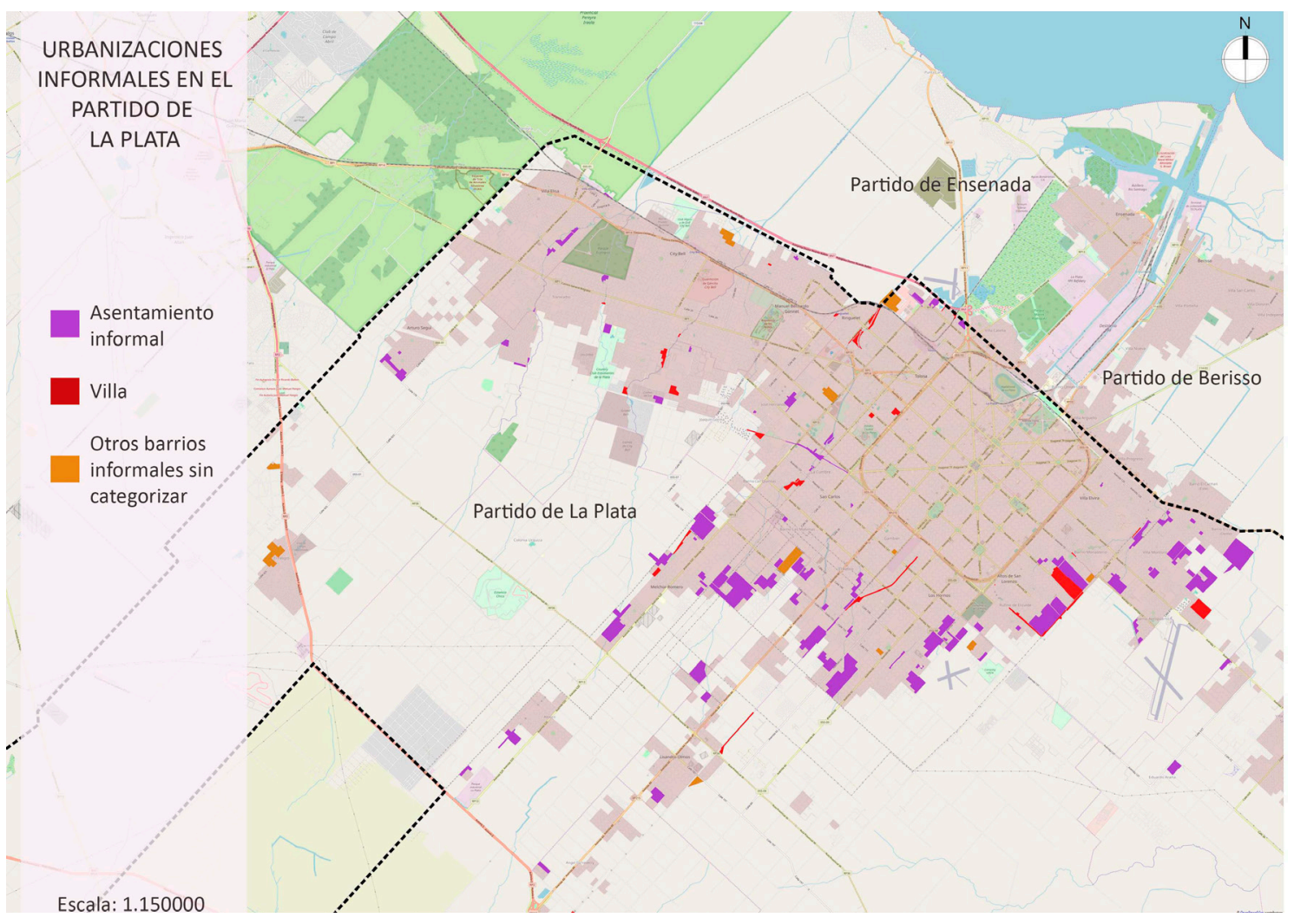

Fuente: Elaboración propia en base a: Registro Provincial de Villas y Asentamientos Precarios. Provincia de Buenos Aires. Año 2015

de habitantes, 195.443 personas (37.7\% residen en el casco fundacional de la ciudad (2807 ha), ocupando el 3,25\% de la superficie total. En las áreas periféricas es donde residen los 458.881 habitantes restantes $(62,3 \%$ de la población total) en 86.080 ha $(96,7 \%)$. En las últimas décadas ha experimentado una creciente expansión urbana, que ha reconfigurado el rol de las periferias de la ciudad, con distintas formas de uso y ocupación del suelo (Figura 1).

Los procesos de crecimiento urbano en el Partido de La Plata adquirieron diferentes modalidades en cuanto al acceso al suelo urbano (Rodríguez Tarducci, 2018). Estas se dan bajo una racionalidad dominante del mercado inmobiliario y de los sectores privados, con una baja intervención del Estado en materia de planificación urbana y adaptación de los servicios y equipamientos. Al mismo tiempo, se da una mayor demanda de nuevas viviendas y tierra accesible para la población, la cual no es atendida por parte del Estado. Es por estos motivos que durante las últimas décadas se ha intensificado la aparición de urbanizaciones informales en la Microrregión del Gran La Plata, las cuales se caracterizan por ser "tomas" masivas de tierras vacantes (fiscales y/o particulares desocupadas). Cabe mencionar que en la microrregión existe una gran cantidad de suelo urbano disponible, en el Partido de La Plata, el 17\% del área urbanizable se encuentra vacante.

Las urbanizaciones informales del Partido de La Plata conviven en las periferias junto con otras formas de ocupación del territorio, conducidas por grupos sociales que presentan distintas lógicas, lo que contribuye a la producción de un territorio desordenado y conflictivo. De este modo, la periferia se convierte en un escenario de disputa en donde se ponen en juego diferentes lógicas de producción del territorio.

En el Partido de La Plata se registraron, en el año 2015, 128 urbanizaciones informales (Figura 2), en las que residen alrededor de 20.800 
Figura 3: Localización de urbanizaciones informales en el Partido de La Plata, según distancia al casco urbano del mismo.

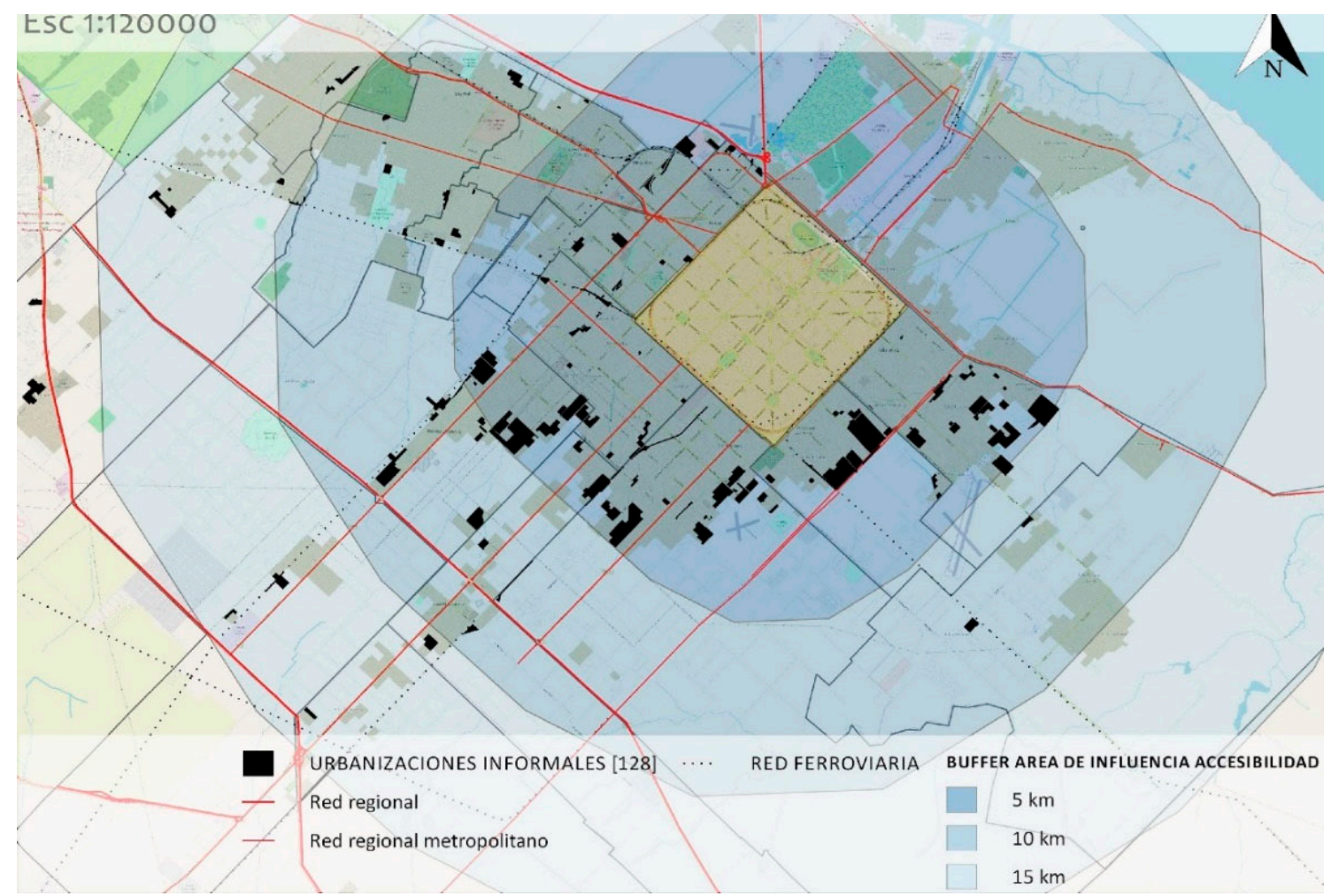

Fuente: Elaboración propia en base a: Registro Provincial de Villas y Asentamientos Precarios. Provincia de Buenos Aires. Año 2015

familias, distribuidas entre asentamiento informal (88), villa (29) y otros barrios informales sin categorizar (11).

En cuanto a la localización, las urbanizaciones informales se ubican mayoritariamente en el primer y segundo cordón del desborde del casco urbano platense, coincidiendo con los límites de la mancha urbana (Figura 3). Se ubican principalmente sobre los ejes sureste y suroeste, correspondientes a las localidades de Villa Elvira, Altos de San Lorenzo, Los Hornos, San Carlos y Melchor Romero. Esta localización arroja una tendencia en relación a las modalidades de ocupación del territorio, ya que dichos ejes de crecimiento presentan mayores condiciones de vulnerabilidad, al mismo tiempo que menor cantidad de recursos en relación a la dinámica socioeconómica del Partido. Del mismo modo, gran cantidad de las urbanizaciones informales del Partido de La Plata se localizan sobre los márgenes de los arroyos (principalmente los Arroyos del Gato y Maldonado), en tierras de alto riesgo ambiental y de inundación, no aptas para el uso residencial, y con dificultades de acceso a las redes de servicios básicos.

En relación a la propiedad de la tierra y la precariedad de las viviendas las urbanizaciones informales en el Partido se caracterizan principalmente por la segregación que sufren sus habitantes por parte del mercado de tierras, al no poder acceder al mismo de manera formal. Esta segregación conduce a la apropiación de terrenos de manera ilegal o al acceso a los mismos a través de un mercado inmobiliario informal. Luego de producirse la toma de los terrenos, generalmente cada familia autoconstruye su vivienda de manera precaria, generalmente en madera, chapa y cartón, aunque pueden reconocerse algunas construcciones con mampostería tradicional. En este sentido, cabe destacar que en el Partido, el 25\% de las urbanizaciones informales se localizan sobre terrenos propiedad fiscal, el 39\% de propiedad privada y el $36 \%$ mixto $^{10}$.

10. Fuente: "Relevamiento de Asentamientos Informales en el 
Figura 4: Falsos vacantes en el Partido de La Plata

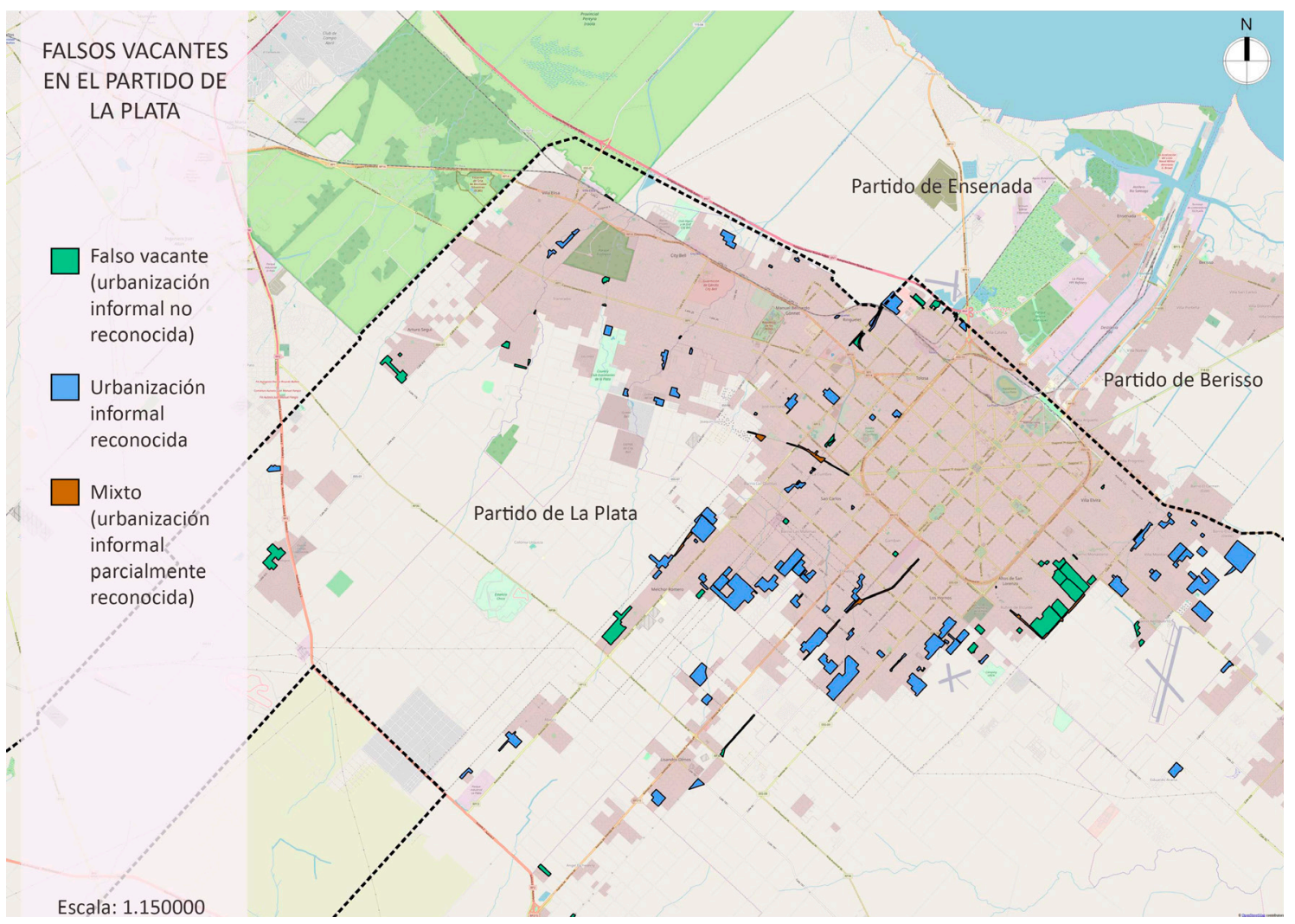

Fuente: Elaboración propia

\section{La problemática de los falsos vacantes en el Partido de La Plata}

A partir de la consideración de la estrecha relación entre la problemática de la ocupación informal y la vacancia del suelo en el Partido de La Plata, se profundiza en el presente apartado en el reconocimiento de los denominados falsos vacantes. Como fuera mencionado en el punto dos de este documento, estas áreas informalmente ocupadas suelen ser consideradas desde distintos estamentos del Estado como espacios vacantes o con ocupaciones transitorias, convirtiéndose en espacios "invisibles" para las administraciones públicas. Cabe recordar, como ya fuera señalado, que en el presente trabajo se ha verificado la condición de lote "vacante" en base a los registros del Ente Provincial ARBA.

Gran La Plata" Argentina "2010 techos para el 2010". Disponible en: http://relevamiento.techo.org.ar/
El análisis de la información primaria y secundaria obtenida permitió realizar una clasificación de la totalidad de urbanizaciones informales, como así también identificar la existencia de falsos vacantes y de otras modalidades de ocupación informal, en un intento de visibilizar y dimensionar esta problemática. En primer lugar, se identifica al "falso vacante" como un barrio informal localizado sobre una tierra que aparece identificada como vacante por el Estado (Ente autárquico provincial encargado de administrar la política tributaria); diferenciándolo de la "urbanización informal" propiamente dicha, es decir, de aquellos barrios reconocidos como informales y que se encuentran localizados sobre una tierra identificada como ocupada por dicho Ente.

Por último, se reconoce la categoría "mixto", que hace referencia a un terreno identificado en su totalidad como vacante pero ocupado parcialmente por una urbanización informal -con una ocupación inferior o igual al 50\%-(Figura 4). Estas categorías resultan de la fotolectura rea- 
Tabla 1: Tipos de Ocupación Informal

\begin{tabular}{|c|c|c|}
\hline TIPO & HA & CANTIDAD \\
\hline Falso vacante (urbanización informal no reconocida) & 273.84 ha & 10 \\
\hline Mixto (urbanizacion informal parcialmente reconocida) & 45.2 ha & 82 \\
\hline Urbanizaciones informales (reconocidas) & 719.42 ha & 128 \\
\hline TOTAL & 1038.46 ha & \\
\hline
\end{tabular}

Fuente: Elaboración propia

lizada parcela por parcela a partir de imágenes satelitales y su constatación con el catastro urbano.

Del análisis se desprende que de la totalidad de urbanizaciones informales presentes en el Partido de La Plata (128), el 28\% son identificados como falsos vacantes (36 urbanizaciones); el 8\% son mixtos (10 urbanizaciones), y el resto, 64\%, son asentamientos informales que aparecen como ocupados (82 urbanizaciones) (Tabla 1).

Entre los falsos vacantes identificados se pueden reconocer las siguientes categorías: en primer lugar, pueden identificarse aquellos barrios que iniciaron un proceso de regularización. Se entiende por proceso de regularización al conjunto variado de herramientas que incluyen leyes, decretos, reglamentaciones, ordenanzas, resoluciones, programas y otros instrumentos de regularización dominial y urbanístico-ambiental. Sin embargo, y como mencionáramos anteriormente, la mayoría de los programas de regularización se hallan desvinculados del resto de las políticas urbanas.

Si bien estas herramientas coinciden en su propósito más general de corregir ex post lo que se define como "irregular", difieren en su contenido específico en la medida en que son formuladas por diversos organismos públicos, involucran a múltiples actores y apuntan a resolver diferentes tipos de irregularidad, según sea en cada caso el modo de acceso al suelo, la situación dominial de partida y el nivel de acatamiento a las normas urbanísticas relativas a la subdivisión del suelo y las construcciones (Relli, 2010).

En el caso de estudio, del total de los falsos vacantes identificados y analizados, sólo 4 de ellos iniciaron algún proceso de regularización. Estos barrios se encuentran ubicados en Ringuelet, Altos de San Lorenzo y Melchor Romero. En segundo lugar, se encuentran los barrios con intervención habitacional, es decir, aquellos que han sido objeto de una mejora del hábitat a través de proyectos de reacondicionamiento del espacio físico (urbano y edilicio) tendiente al logro de una mayor inclusión social y mejoramiento de la calidad de vida de sus habitantes. Se identificó que sólo 7 del total de los falsos vacantes del Partido tuvieron algún tipo de intervención habitacional. Por último, existen los barrios con expropiaciones, las cuales se enmarcan dentro de la Ley Nacional de Expropiación No 21.49911. Del total de los falsos vacantes identificados y analizados en este trabajo, sólo 2 de ellos figuran como barrios con expropiaciones. Estos barrios se encuentran ubicados en la localidad de Altos de San Lorenzo.

Del análisis realizado se pone de manifiesto que los falsos vacantes en el Partido de La Plata constituyen una parte significativa de la periferia, tanto por la cantidad como por la superficie que ocupan, siendo el resultado de la presión por el

11. Ley Nacional de Expropiación No 21.499 Recuperado de: http://servicios.infoleg.gob.ar/infoleglnternet/anexos/35000-39999/37292/norma.htm 


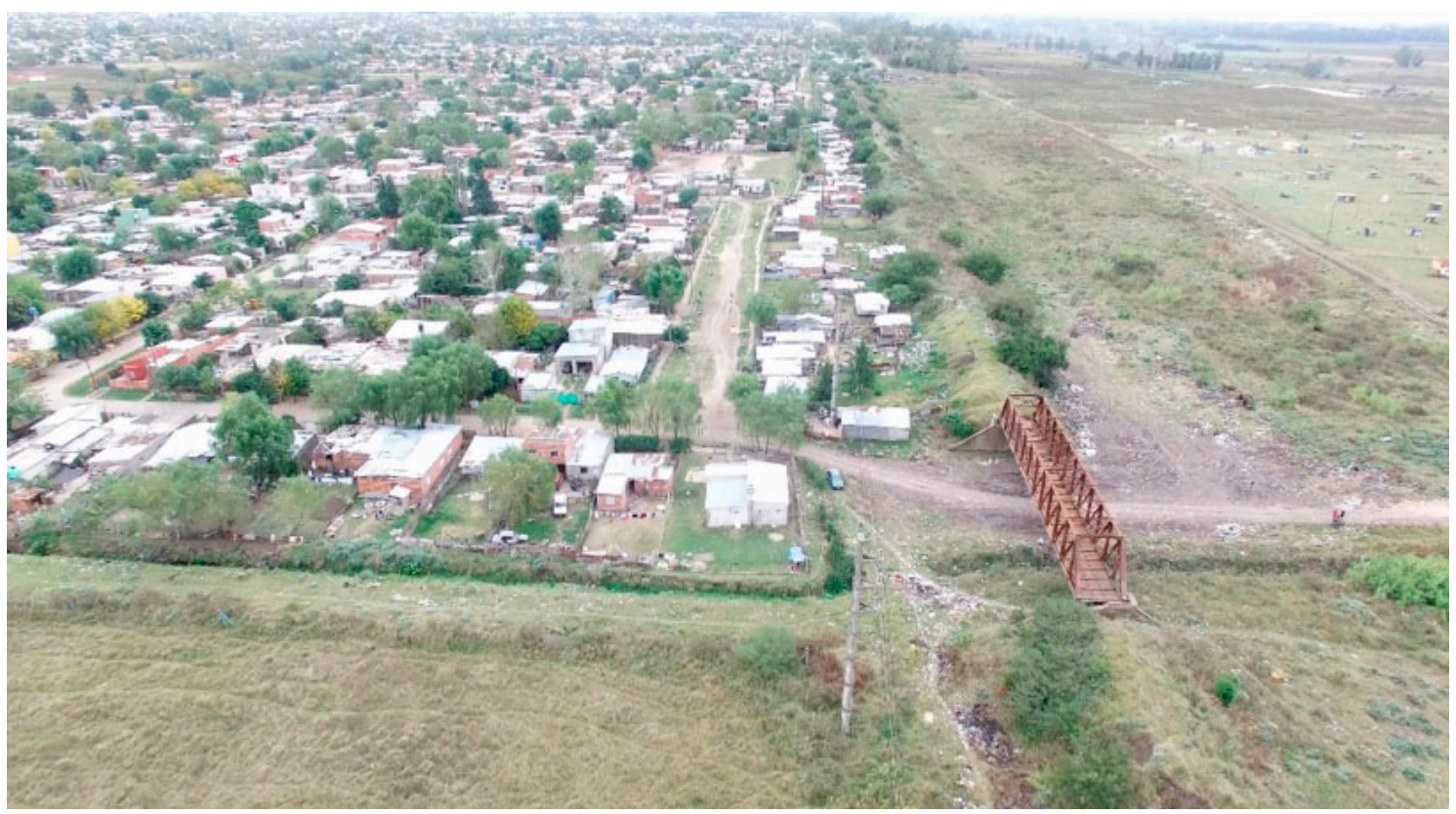

Fuente: Tomás Canevari, 2017

acceso al suelo. Los falsos vacantes contribuyen a la construcción de la no-ciudad, es decir, a una urbanización sin ciudad, en donde la urbanización informal es una parte constitutiva de este proceso. La falta de reconocimiento de los asentamientos informales contribuye a la ausencia de un espacio con identidad y, como señala Augé (2000) un espacio sin identidad no puede definirse ni como espacio relacional ni como histórico. Frente a un Estado que se caracteriza -al interior de la problemática planteada- por una baja intervención y por la falta de una idea integral de planificación territorial, el reconocimiento de esta compleja realidad desde los distintos estamentos del Estado, resulta esencial para poder intervenir en estos asentamientos y garantizar a sus habitantes el derecho a la ciudad, superando las actuales periferias incompletas, heterogéneas y degradadas.

\section{El Barrio Puente de Fierro como un falso vacante}

El Barrio Puente de Fierro, localizado en Altos de San Lorenzo en la periferia sur del Partido de La Plata, surge como urbanización informal durante la década de los 90, aunque su impronta tiene un pasado más extenso ligado a la dicta- dura militar Argentina y al pasado ferroviario de la Región. Comenzó a poblarse durante 1940 y 1950, producto de los primeros loteos, adquiridos, fundamentalmente, por empleados del ferrocarril y hasta la década de 1970 funcionó la Estación Central del Ferrocarril Provincial.

Este barrio, en la actualidad es considerado uno de los más importantes del Partido de La Plata presentando una extensión de alrededor de 60 hectáreas en las que habitan aproximadamente1500 familias en condiciones de pobreza y vulnerabilidad.

La ubicación del barrio hace que se encuentre a un "costado" y "marginado" de las mayores inversiones urbanas y de las principales vías de comunicación.

Por este motivo, Puente de Fierro no forma parte de los recorridos habituales de los habitantes del centro y de otras áreas de la ciudad, encontrándose invisibilizado en las representaciones acerca de la ciudad. La escasa visibilización que se le ha dado en ocasiones al barrio ha sido generalmente a través de algunos medios de prensa locales, por cuestiones relacionadas a delitos y carencias de infraestructura. 


\section{FALSOS VACANTES}

ß

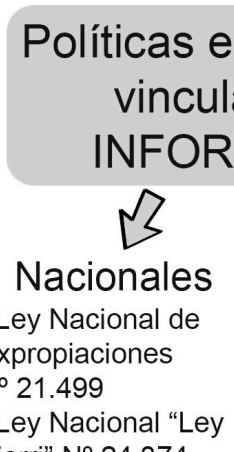

Pierri” N ${ }^{\circ} 24.374$

Fuente: Elaboración propia

Los propios habitantes del barrio reconocen que "no figuran en el mapa"12 a pesar de contar con múltiples organizaciones sociales y vecinales trabajando en conjunto dentro del mismo. El barrio Puente de Fierro puede ser considerado un "falso vacante" al encontrarse invisibilizado en la cartografía oficial de la Agencia de Recaudación de la Provincia de Buenos Aires, a pesar de albergar una gran cantidad de familias y ser uno de los asentamientos informales más importantes del Partido.

\section{¿Qué hacer frente a los falsos vacantes?: Algu- nas herramientas de intervención estatal}

Abordar desde el Estado la problemática de los falsos vacantes en el Partido de La Plata implica trabajar conjuntamente en políticas e instrumentos vinculados con dos temas: por un lado, la informalidad urbana y por el otro, la tierra vacante (Figura 6).

En relación a la informalidad urbana, durante los últimos años, se ha manifestado un inci-

12. Documento audiovisual completo disponible en : https:// www.youtube.com/watch?v=F1xHPFKvdlA piente interés por visibilizar la problemática desde algunos organismos del Estado. En este sentido, a nivel provincial, la Ley de Acceso Justo al Hábitat No $14.449^{13}$ promulgada en el año 2013, establece un marco legal institucional que se encuentra íntimamente relacionado con la problemática de estudio. Entre sus lineamientos generales se encuentra el de "ejecutar proyectos de integración socio-urbanística de villas y asentamientos precarios". Como así también el "impulso a la integración socio-urbanística y a la regularización de la tenencia de la tierra en villas y asentamientos precarios con la finalidad de hacer efectiva la incorporación de la propiedad del suelo como un derecho de los habitantes".

El artículo 44 de la ley 14.449 establece que los planes y normas urbanísticas municipales establecerán zonas especiales y reservas de tierras en predios vacantes u ocupados, con la finalidad de asegurar las condiciones legales para la puesta en marcha de procesos de regularización urbana y dominial, resguardar

13. Ley de Acceso Justo al Hábitat No 14.449. Recuperado de: http://www.mosp.gba.gov.ar/subsecretarias/informacion/ Ley14449.pdf 
la permanencia de la población residente y promover la construcción de viviendas y urbanizaciones sociales planificadas (Frediani, 2016).

En el marco de esta ley se ha elaborado un Registro Público Provincial de Villas y Asentamientos Precarios, en donde se muestra la localización, tamaños, cantidad de familias, acceso a servicios, entre otros datos. Pese a la existencia de esta herramienta, aún los habitantes de las urbanizaciones informales no se sienten plenamente visibilizados, ya que la ley y las herramientas que propone funcionan desarticuladas de otras políticas y organismos del Estado a través de los cuales se podría dar una respuesta más integral en relación con la problemática.

Asimismo, con motivo de la Ley de Acceso Justo al Hábitat, en el presente año se creó, en la Provincia de Buenos Aires, el Organismo Provincial de Integración Social y Urbana (OPI$\mathrm{SU})$, cuya misión es "velar por la promoción del derecho a la vivienda y a un hábitat digno y sustentable, a través de la creación de barrios en donde se encuentran ubicados núcleos habitacionales en estado de precariedad, logrando así una plena integración de éstos a la trama de los Municipios de la Provincia de Buenos Aires".

Al mismo tiempo, en relación a las herramientas de intervención estatal cabe destacar el Programa de Mejoramiento de Barrios (PROMEBA) que tiene como objetivo mejorar la calidad de vida y contribuir a la inclusión social e integración de los hogares argentinos de los segmentos más pobres de la población, que residen en villas y asentamientos irregulares. Su propósito es mejorar de modo sustentable el hábitat de los hogares residentes en villas y asentamientos irregulares del país a través de la legalización de la tenencia de la tierra, la provisión de estructura básica y el desarrollo comunitario ${ }^{14}$.

Por otro lado, existen marcos legales nacionales en relación a la problemática de la tenen-

14. Fuente: https://www.promeba.gob.ar/ cia irregular de la tierra. En primer lugar, la Ley Nacional de Expropiación No21.499 menciona que "pueden ser objeto de expropiación todos los bienes convenientes o necesarios para la satisfacción de la "utilidad pública", cualquiera sea su naturaleza jurídica, pertenezcan al dominio público o al dominio privado, sean cosas o no". En esta misma línea, se encuentra la Ley Nacional No 24.374 (denominada "Ley Pierri" $)^{15}$, sancionada en el año 1994, que establece un régimen de regularización dominial en favor de ocupantes que acrediten la posesión pública, pacífica y continua durante 10 años, y su causa lícita, de inmuebles urbanos que tengan como destino principal el de casa habitación única y permanente.

En el artículo 7 se establece que cuando los inmuebles fuesen de dominio del Estado nacional, provincial o municipal, se procederá a la inmediata escrituración por intermedio de las escribanías habilitadas. Cabe mencionar que la denominada "Ley Pierri" es una de las herramientas más utilizadas por los habitantes de barrios informales para acceder la titularidad de los terrenos.

En relación a la vacancia del suelo, existen distintos instrumentos a nivel provincial para abordar la problemática. Tanto en el Decreto/ Ley 8912 como en la Ley de Acceso Justo al Hábitat, aparece el instrumento denominado "Edificación y parcelamiento obligatorios", el cual le permite a los municipios exigirle a los propietarios de tierras vacantes que edifiquen o parcelen su terreno, de acuerdo a lo establecido en la ordenanza municipal. En el caso de que el propietario incumpla, el municipio puede aplicar un gravamen especial de carácter progresivo, durante cinco años, y si luego del plazo persiste la falta de parcelación y/o edificación, la tierra queda declarada de utilidad pública y el municipio puede proceder a la expropiación. El fin es disminuir la especulación del suelo.

Otro instrumento interesante es la declaración de Zonas de Promoción del Hábitat Social, en

15. Ley Nacional No 24.374 Recuperado de: http://servicios.infoleg.gob.ar/infoleglnternet/anexos/0-4999/755/texact.htm 
donde la tierra vacante solo puede ser utilizada para la construcción de viviendas y urbanizaciones sociales planificadas. De este modo se busca incrementar la producción de viviendas de interés social, a través del aumento de la oferta de áreas urbanizadas, y proteger los intereses de los sectores populares.

Por otro lado, se puede mencionar el Impuesto Progresivo al Lote baldío, en donde se aplica un tributo / impuesto a los propietarios de las tierras vacantes que se localizan al interior de la ciudad. El objetivo de este instrumento es desalentar la especulación inmobiliaria, incentivando la construcción y el desarrollo productivo.

A nivel nacional, las leyes No 26.994 y $N^{\circ}$ 24.320 permiten la regularización dominial de tierra vacante (ociosa o abandonada) sobre la que los municipios ya ejercían derechos posesorios, en las cuales no existe un propietario o poseedor de la tierra.

De este modo, en caso de que una tierra pertenezca al dominio privado, pero sobre el mismo ejerza la posesión real el Estado (a través de organismos provinciales o municipios), la Ley $N^{\circ} 24.320$ establece la posibilidad de efectuar un trámite administrativo que permite incorporar su titularidad y pleno derecho a disponer de él por parte de la Provincia o municipio que lo poseyó. Esta Ley Nacional regula el procedimiento mediante el cual los municipios pueden adquirir el dominio de inmuebles a través de esta vía, sin necesidad de seguir la judicial, y le permite al Estado, que si tiene la posesión de una tierra de forma pública, pacífica y continua durante 20 años, pueda quedarse con la propiedad.

\section{Reflexiones Finales}

A partir del análisis realizado se puede reconocer que gran parte de las urbanizaciones informales del Partido de La Plata, un tercio del total, constituyen los denominados "falsos vacantes", es decir, tierras consideradas vacantes para el Estado pero que presentan un uso real como asentamiento informal o villa. Esto implica que se trata de una problemática no debidamente visibilizada para la población en su totalidad, y para el Estado en particular, con la consecuente falta de una respuesta que apunte a resolver esta situación.

La respuesta a la pregunta planteada al inicio del trabajo acerca de si la invisibilidad de estos barrios determina la ausencia o escasez de políticas que permitan atender a las necesidades de sus habitantes o si la falta de respuesta a esta problemática desde el Estado les proporciona invisibilidad a estos asentamientos, pone de manifiesto que se trataría de estas dos cuestiones simultáneamente, estableciéndose entre ambas una relación dialéctica.

Las herramientas de intervención estatal -tanto a nivel nacional como provincial- que abordan la problemática de la informalidad urbana, funcionan desarticuladamente entre sí, dificultando la posibilidad de una respuesta integral al problema.

La escasa y desarticulada información acerca de las urbanizaciones informales se constituye en uno de los problemas centrales, que dificulta la respuesta desde el Estado. Al realizar el análisis de la información disponible en distintas plataformas, se pudo identificar que, en parte, existen herramientas que están disponibles y que las comunidades organizadas pueden hacer grandes aportes con pequeñas acciones. En este sentido, el caso de Puente de Fierro, una de las urbanizaciones informales más grandes del Partido, puede ser considerado un falso vacante. Sin embargo, y pese a esta situación, cuentan con múltiples organizaciones sociales y vecinales trabajando al interior del barrio en pos de revertir esta falta de visibilidad y reconocimiento.

En este sentido, el presente trabajo intenta contribuir, mediante la identificación y el análisis de los falsos vacantes a la visibilización de esta problemática, aportando un diagnóstico actualizado que oriente a los organismos del Estado (en particular a los gobiernos municipales) en la implementación de soluciones y políticas integrales que respondan a las necesidades de los habitantes de urbanizaciones informales 


\section{Bibliografía}

Augé, Marc (2000). Los no lugares: espacios del anonimato: antropología sobre modernidad. Barcelona: Gedisa.

Biedermann, A.; Sebastián, F.; Sanz Ferreruela, F. (Coords.) (2018). En los márgenes de la ciudad, del arte y de la crítica. Zaragoza: Ed. Prensas de la Universidad de Zaragoza.

Cáceres, R.; Cáceres, E. (2016). Identidades invisibles, ¿o invisibilizadas? Reflexiones sobre la formación de identidad y sentido de lugar en las periferias urbanas vulneradas. Revista del Taller de Estudios de la Ciudad y Territorio, 2 (2016), 44-45. Recuperado de

Clichevsky, N. (2000). Informalidad y segregación urbana en América Latina. Una aproximación. Serie Medio Ambiente y Desarrollo No28. Santiago de Chile: CEPAL.

Clichevsky, N. (2006). Regularizando la informalidad del suelo en América Latina y el Caribe. Una evaluación sobre la base de 13 países y 71 programas. Santiago de Chile: CEPAL.

Clichevsky, N. (2007). La tierra vacante "revisitada". Elementos explicativos y potencialidades de utilización. Cuaderno Urbano N6, 195-219.

Cravino, M. C. (Org.). (2008). Los mil Barrios Informales. Buenos Aires: Universidad Nacional de General Sarmiento.

Delgado, M. (2003). La No-Ciudad como ciudad absoluta. En: Sileno: Variaciones sobre arte y pensamiento, № 14-15, 2003, págs. 123-131.

Fausto, A.; Rábago, J. (2002). ¿Vacíos urbanos o vacíos de poder metropolitano? Boletín CF+S, No21, 1-12. Recuperado de http:// habitat.aq.upm.es/boletin/n21/aafau.html

Frediani, J. (2010). Lógicas y tendencias de la expansión residencial en áreas periurbanas. El Partido de La Plata, Buenos Aires, Argentina, entre 1990 y 2010. (Tesis doctoral). Universidad Nacional de La Plata. Facultad de Humanidades y Ciencias de la Educación. La Plata. Recuperado de http://www.fuentesmemoria.fahce.unlp.edu.ar/tesis/te.355/te.355.pdf

Frediani, J. (2016). La política de manejo de la tierra vacante en el Gran La Plata, Buenos Aires. Cuaderno Urbano, Espacio, Cultura, Sociedad, 20, N²0, 27-44.

Hidalgo, R.; Borsdorf, A.; Zunino, H.; Álvarez, L. (2008). Tipologías de expansión metropolitana en Santiago de Chile: precariópolis estatal y privatópolis inmobiliaria. 1999-2008. Scripta Nova. vol. XII, nº 270 (113). Recuperado de http://www.ub.es/geocrit/sn/sn-270/ sn-270-113.htm, https://revistas.unc.edu.ar/index.php/tecyt/article/download/15434/15311

Larangeira, A. (2004). Tierra vacante en las ciudades de América Latina: Desafíos y Oportunidades. Cambridge: Lincoln Institute of Land Policy.

Relli, M. (2010). Regularización dominial en la Provincia de Buenos Aires, 1990 - 2005. En: III Jornadas del Doctorado en Geografía. Desafíos Teóricos y Compromiso Social en la Argentina de Hoy, La Plata. Recuperado de http://www.memoria.fahce.unlp.edu.ar/ trab_eventos/ev.1498/ev.1498.pdf

Rodríguez Merkel, G. M. (2014). Qué es y qué no es segregación residencial. Contribuciones para un debate pendiente. Biblio 3W. Revista Bibliográfica de Geografía y Ciencias Sociales. Barcelona: Universidad de Barcelona, 25 de junio de 2014, Vol. XIX, n 1079. Recuperado de http://www.ub.es/geocrit/b3w-1079.htm

Rodríguez Tarducci, Rocío. (2018). Asentamientos informales en el Partido de La Plata: Una aproximación a las modalidades de ocupación del territorio. Estudios Socioterritoriales, 23 Recuperado de http://www.scielo.org.ar/scielo.php?script=sci_arttext\&pi$d=$ S1853-43922018000100008\&lng=es\&tlng=es.

Tardin, R. (2006). La Ciudad Informal. En: Nogué, J.; Romero, J. (Org.). Las Otras Geografías (389-404).Valencia: Editorial Tirant lo Blanch.

Viana, I. (2007). Informalidad, Regularización y Derecho de Propiedad. En: Smolka, M.; Mullahy, L. (Eds.). Perspectivas Urbanas. Temas críticos en políticas de suelo en América Latina. (65-143). Cambridge: Lincoln Institute of Land Policy.

Welch Guerra, Max (2005). Buenos Aires a la deriva: transformaciones urbanas recientes. Buenos Aires: Biblos. 